\title{
PD03 - Household smoking and markers of atopic sensitisation in children: a systematic review and meta-analysis
}

\author{
Wojciech Feleszko*, Marek Ruszczyński, Joanna Jaworska, Agnieszka Strzelak, Bartłomiej M Zalewski, Marek Kulus
}

From 3rd Pediatric Allergy and Asthma Meeting (PAAM)

Athens, Greece. 17-19 October 2013

\section{Background}

Household smoking (HS) is linked in children with development and aggravation of allergic asthma. Its influence on children's immune responses and development of allergy has not been conclusively elucidated.

\section{Objective}

To perform a systematic review evidence of HS on markers of allergic sensitization in children and adolescents.

\section{Methods}

CENTRAL, MEDLINE, and EMBASE databases were searched in November 2012. Included studies compared environmental tobacco smoke-exposed and non-exposed children and fulfilled criteria to define objective markers of atopic sensitization defined as total immunoglobulin E concentrations (tIgE), presence of specific $\operatorname{IgE}(\operatorname{sgE}+)$, and positive skin-prick tests (SPT+). A standardized protocol was used for data extraction. Resulting data were analyzed by methods of fixed or random-effect model, and generic inverse variance analysis (RefMan software). evident in the preschool children $(<7 \mathrm{y})(\mathrm{OR}=1.20$; and $\mathrm{OR}=1.33$ for sIgE + and $\mathrm{SPT}+$, respectively).

\section{Conclusions}

This analysis underscores the association between HS in early childhood and augmented risk of allergic sensitization, and that early age of children is related to its harmful immune-modulating effects of parental tobacco smoking. Furthermore this study highlight again the role of environmental tobacco smoke exposure as the most important, avoidable risk factors for development of allergy in children.

Published: 28 February 2014

\section{doi:10.1186/2045-7022-4-S1-P3}

Cite this article as: Feleszko et al:: PD03 - Household smoking and markers of atopic sensitisation in children: a systematic review and meta-analysis. Clinical and Translational Allergy 2014 4(Suppl 1):P3.

\section{Results}

8 studies of HS influence on tIgE concentration (2,603 children), 6 studies on HS and sIgE+ (9,844 children) and 14 studies of ETS and SPT (14,176 children) met the preset criteria of inclusion. Parental tobacco smoking was shown to raise tIgE concentrations by average of $27.7 \mathrm{IU} / \mathrm{ml}(95 \% \mathrm{CI}: 7.8-47.7)$ and to boost the risk of atopic sensitization, as assessed by $\operatorname{sgE}+(\mathrm{OR}=1.12$, 95\%CI: $1.00-1.25)$ and SPT+(OR=1.13; 95\%CI: 1.02-1.26). According to a subgroup analysis, this effect became

\footnotetext{
The Medical University of Warsaw, Warsaw, Poland
}

Submit your next manuscript to BioMed Central and take full advantage of:

- Convenient online submission

- Thorough peer review

- No space constraints or color figure charges

- Immediate publication on acceptance

- Inclusion in PubMed, CAS, Scopus and Google Scholar

- Research which is freely available for redistribution

Submit your manuscript at www.biomedcentral.com/submit C Biomed Central 